\title{
CHILE COMO UN "FLANDES INDIANO" EN LAS CRÓNICAS DE LOS SIGLOS XVI Y XVII ${ }^{1}$
}

\author{
Álvaro Baraibar \\ GRISO - Universidad de Navarra \\ abaraibar@unav.es
}

RESUMEN / ABSTRACT

La idea de un nuevo Flandes o de un segundo Flandes o simplemente de otro Flandes apareció en diferentes momentos en el territorio de la Monarquía Hispánica referida a Aragón, Cataluña o Messina. El recuerdo de la guerra pervivió en el imaginario colectivo español más allá del final del conflicto, cuando Flandes era ya un aliado de la Corona española frente a Francia. Cuando en el desarrollo de la conquista de las Indias Occidentales Chile se convierte en el gran problema militar con motivo de la resistencia de los indígenas de la Araucanía, la idea de un segundo Flandes aparecerá también en tierras americanas. Este trabajo pretende mostrar el proceso y los contextos en que Flandes se hizo presente en el discurso que se elaboró sobre el Reino de Chile en las crónicas de los siglos XVI y XVII, hasta que Diego de Rosales acuñara el término "Flandes indiano".

Palabras clave: Crónicas de Indias, reino de Chile, guerra, Flandes.

The idea of a new Flanders or of a second or simply of another one appeared in different moments in the territory of Hispanic Monarchy referred to Aragón, Catalonia or Messina. The memory of this war survived in the Spanish collective imaginary even long after the end of the conflict, when Flanders was an ally of the Spanish Crown against France. When Chile becomes the great military problem due to native resistance to conquest, the idea of a second Flanders will turn up in America. This article tries to show the process and contexts

1 Este trabajo forma parte de los resultados del proyecto HAR2012-31536, Discurso y poder, lengua y autoridad en el mundo hispánico (siglos XVI-XVII), subvencionado por el Ministerio de Economía y Competitividad. 
in which Flanders becomes visible in the discourse elaborated around the kingdom of Chile in the chronicles of 16th and 17th Centuries, until Diego de Rosales, the first writer to use the term "Indian Flanders".

KEY WORDS: Chronicles of the Indies, Kingdom of Chile, War, Flanders, Dutch Revolt.

\section{INTRODUCCIÓN}

Tenemos constancia, tanto en documentos históricos como en obras literarias, de lo que evocaba Flandes en el imaginario colectivo español a finales del siglo XVI y a lo largo del siglo XVII. Flandes era el gran problema irresoluble, permanente, de la Corona española; era también sinónimo de una guerra sin fin, de sufrimiento y de muchas muertes para las tropas españolas; era sin lugar a dudas el luterano, contra el que debía luchar la fe católica. Flandes representaba, en definitiva, al enemigo de España, al menos hasta la firma del tratado de paz de Münster de 1648, momento en que la política internacional española cambió, a raíz de la creciente amenaza francesa ${ }^{2}$. A pesar del final de la guerra y de que en 1673 Holanda pasaría a ser un aliado de España en su común enfrentamiento con la Francia de Luis XIV, la imagen de Flandes como problema español por antonomasia perviviría todavía en el recuerdo durante mucho tiempo.

Buen ejemplo de ello es precisamente el hecho de que la imagen de Flandes se traslade y aplique al proceso de conquista de Chile y a la guerra de la Araucanía. La expresión "Flandes indiano" se ha convertido en un lugar común, en una forma más o menos exitosa con la que referirse a Chile. Desde que fuera acuñada por el jesuita Diego de Rosales allá por 1674 -fecha en la que pudo haber concluido su Historia general del reino de Chile. Flandes indiano (Vicuña Mackenna XXXIII)-, la expresión ha sido utilizada en muy diferentes textos, bien para referirse al propio país en su conjunto, bien como forma de hablar del periodo colonial del Reino de Chile. "Flandes indiano" se ha convertido en el recurso al que han acudido diferentes autores a la hora

2 Sobre esta cuestión en particular versó la intervención de J. $\mathrm{M}^{\mathrm{a}}$. Usunáriz en el congreso internacional "Imagen y realidad: el universo simbólico del poder en el Siglo de Oro" (Pamplona, 12-14 de diciembre de 2011) con el título "La imagen del enemigo exterior en las crónicas y relaciones de sucesos del siglo XVI". Ver también Usunáriz, "América en la política..." citado en la bibliografía. 
de titular obras y capítulos de libros de temática muy variada. Creo que es interesante hacer un breve repaso de algunos casos, aunque solo sea como un pequeño listado de ejemplos -sin el menor ánimo de exhaustividad-que ilustren un uso contemporáneo, actual, de la expresión.

El historiador y arquitecto chileno fray Gabriel Guarda la ha empleado en más de una ocasión al hablar de las fortificaciones del Reino de Chile y se ha referido a los conquistadores del país trasandino en la época colonial como los "guerreros del Flandes indiano". Otros autores han caminado por una senda similar al hablar del legado medieval en el arte y la sociedad chilenos entre 1550 y 1650 o sobre las reformas de los Borbones en Chile en la segunda mitad del siglo XVIII ${ }^{4}$. Especialmente significativo me parece, en este sentido, el caso de Lázaro Ávila, que tituló Las fronteras de América y los "Flandes indianos" un libro publicado en 1997, en el que afirmaba que la "importancia y gravedad" de las luchas provocadas por los intentos de conquista del territorio americano por parte de los españoles explican que "estos conflictos fronterizos se convirtieran paulatinamente en los onerosos y sangrientos 'Flandes' de la Corona española en América” (Lázaro Ávila 14) 5

Es evidente, por tanto, el éxito contemporáneo de la expresión referida al período colonial chileno, pero cabe preguntarse: ¿qué mensaje quiso condensar Rosales en aquellas dos palabras? ¿La mención de Flandes era una referencia vaga y general que evocaba las constantes y permanentes luchas en la Araucanía o se trata de una construcción más elaborada con paralelismos concretos que recuerdan pasajes o lugares de la guerra con los Países Bajos? Y, por otro lado, ¿la fórmula fue una invención del propio Rosales o fue el resultado de un proceso histórico en el que dicha imagen fue cobrando forma? Por último, ¿cuál era el sentido de esta afirmación, cuando a la altura de 1674 los Países Bajos eran ya más un aliado que un enemigo?

3 Ejemplo de ello es el título de uno de sus libros, Flandes indiano. Las fortificaciones del Reino de Chile, 1541-1826. La expresión referida a los conquistadores la encontramos como título de uno de los epígrafes de otro de sus libros: Guarda, Los laicos 197-207.

Isabel Cruz de Amenábar (1986) tituló un apartado de su libro como "El Flandes indiano y su legado medieval, 1550-1560" y por su parte Jaques A. Barbier (1980) dedicó su primer capítulo al "Flandes Indiano".

Un caso diferente es el trabajo de Nunes Adão (2006) titulado "Chile holandés o Flandes indiano en la visión de Gaspar Barléu”, en el que reserva la expresión para referirse al proyecto holandés de asentarse en el país trasandino. 


\section{LA IMAGEN DE UN SEGUNDO FLANDES EN LA PENÍNSULA}

Antes de recalar en el continente americano, es imprescindible hacer referencia a algunos momentos históricos peninsulares y europeos en los que la imagen de Flandes como enemigo por antonomasia de la Corona española fue utilizada también como recurso discursivo. La idea de un nuevo Flandes o de un segundo Flandes o simplemente de otro Flandes era algo que ya había tomado forma en España y que se manifestó expresamente en diversa documentación. Aparece aplicado a Aragón a finales del siglo XVI, concretamente con motivo de los sucesos acaecidos tras la huida de Antonio Pérez, secretario de Felipe II, al territorio foral ${ }^{6}$. Y reaparece casi medio siglo después, en 1642, en el marco de la sublevación de Cataluña. Tras la pérdida de Perpiñán ante las tropas francesas ayudadas por los catalanes, el 13 de septiembre de aquel año Gil González Dávila, cronista de Castilla, escribía una carta que se iniciaba con las siguientes palabras:

Señor mío: Cataluña -en el juicio de los muy prudentes- será el segundo Flandes de España, que acabe con lo poco que queda de sustancia y vida. Teníamos la gota en los pies (la guerra en Flandes) y no hemos podido apartarla de nosotros. Hémosla traído a la cabeza. ¿Cuándo sanaremos de ella? ${ }^{7}$

Avanzado ya el siglo XVII, en el contexto de las insurrecciones del virreinato de Sicilia de los años setenta, el inquisidor Sebastián de Mongelos se refería a la necesidad de resolver lo antes posible las revueltas en Messina (1673), ya que "si no se remedia será otro Flandes"8. Los Países Bajos eran un aliado de la Corona española desde el año anterior, pero el recuerdo de la guerra de Flandes se mantendría todavía muy vivo durante mucho tiempo.

Por otro lado, Flandes también ha dado lugar a algunos refranes o expresiones populares que muestran igualmente la presencia del conflicto

6 Gregorio Marañón cita dos cartas del verano de 1591 en las que desde la Corte se enviaban "algunos avisos angustiosos" acerca de que "en Aragón se preparaba 'otro Flandes"” (Marañón, vol. II: 559).

La carta está fechada el 13 de septiembre de 1642 (M.T.A., "Noticiario del siglo XVII" 351). De fecha cercana -16 de mayo de 1641- es otra referencia similar que podemos ver en el "Diario del ejército español en las comarcas de Tarragona" (442): "a menos será esto otro Flandes, obligando a estar siempre con las armas en la mano".

Carta del inquisidor Sebastián de Mongelo (cit. en Rivero Rodríguez 284). 
bélico con las provincias unidas en la memoria y el imaginario colectivo de los españoles de los Siglos de Oro. Este es el caso, por ejemplo, del refrán "España mi natura, Italia mi ventura y Flandes mi sepultura", recogido por Correas en su Vocabulario de refranes y frases proverbiales publicado en $1627^{9}$. Resulta muy interesante comprobar cómo a refranes que transmitían una imagen positiva de Flandes sucedieron otros en que la brutalidad de la guerra se terminó por imponer. Muy expresivo de esta realidad es el caso de la frase "No hay más Flandes", recogida también por el propio Correas con los sentidos de 'alabar cosa galana y de placer' y 'encarecer cosa buena y hermosa' ${ }^{10}$, cuando vemos lo que dice al respecto Francisco de Quevedo en su Pregmática de aranceles generales:

Los que, estando en alguna conversación de regocijo, dicen "No hay más Flandes", por encarecimiento de gusto, les condenamos a que sean desdichos en presencia de hermano mayor y hermandad, pues hasta ahora no hemos visto de aquellos estados cosa de entretenimiento, sino ojos sacados, tuertos, o brazos quebrados y piernas (Quevedo, Pregmática de aranceles generales 174).

Como podemos comprobar, Flandes evocaba en diferentes momentos del siglo XVI y XVII fundamentalmente la imagen de la guerra, del conflicto bélico. Aunque el argumento de la lucha contra el luteranismo fue elevado a la condición de criterio por el que debía regirse la política exterior española y fue esgrimido insistentemente por parte de quienes explicaban y justificaban la lucha en los Países Bajos (Usunáriz 2011), el hecho de que en distintos momentos el recuerdo de Flandes se aplicara a las católicas Aragón, Cataluña o Sicilia nos habla más de la guerra y del coste que esta tenía en vidas y recursos que de un problema religioso.

9 Correas, Vocabulario de refranes y frases proverbiales, refrán 9716. Hay otros casos interesantes también en este mismo autor que hacen referencia a Flandes asociado a problemas: "la sardina de Flandes, que huyendo de las llamas dio en las brasas" (refrán 20793), en el sentido de pasar de un peligro a otro mayor; "O todo a Flandes, o todo a fondo" (refrán 17233), expresando el esfuerzo y la voluntad de conseguir algo a toda costa.

10 Correas, Vocabulario de refranes y frases proverbiales, refranes 4762, 16162 y 16163. Covarrubias, en su Tesoro de la lengua castellana o española recoge la expresión también y explica que se emplea "para encarecer una cosa de mucho deleite" por ser aquella tierra "tan fértil y abundante y amena, y la gente tan jovial y política", Covarrubias, Tesoro 912. 


\section{EL RECUERDO DE FLANDES DE LAS CRÓNICAS CHILENAS DEL XVI Y XVII}

Cuando, en el desarrollo de la conquista de las Indias Occidentales, Chile se convierte en el gran problema militar con motivo de la resistencia de los indígenas de la Araucanía, la idea de un segundo Flandes aparecerá también en tierras americanas. Resulta muy ilustrativo tratar de analizar el sentido que diferentes autores, historiadores del Reino de Chile, dieron a Flandes y las comparaciones que establecieron entre los Países Bajos y el que se daría en llamar "Flandes indiano" ". Son igualmente significativos otros silencios, el hecho de que haya un cierto número de crónicas en que no encontremos tales referencias. Se trata concretamente de las obras de Pedro de Valdivia, Jerónimo de Vivar, Alonso de Góngora Marmolejo y Alonso de Ovalle. Salvo el caso de Ovalle, el resto son obras muy tempranas, anteriores incluso al inicio mismo de la guerra de Flandes, y si las hemos tenido en cuenta ha sido para poder fijar la imagen de Flandes anterior a la rebelión contra la Corona. Además de los autores mencionados, otros como Mariño de Lobera y Alonso González de Nájera sí hacen referencias a Flandes y lo comparan con Chile, pero se trata de contextos, como veremos, bien distintos al de Diego de Rosales. Con todo, antes de que el jesuita hablara del "Flandes indiano" hubo otras plumas que sí aludieron a Chile como un "nuevo Flandes", un "segundo Flandes". Trataré de mostrar de qué manera y con qué sentidos se estableció en cada caso esa comparación entre Chile y Flandes.

11 El corpus de textos que he tenido en cuenta para el presente trabajo comprende las siguientes obras: Pedro de Valdivia, Cartas de don Pedro de Valdivia al emperador Carlos $V$ (1545-1552); Jerónimo de Vivar, Crónica y relación copiosa y verdadera de los reinos de Chile (1558); Alonso de Góngora Marmolejo, Historia de todas las cosas que han acaecido en el Reino de Chile y de los que lo han gobernado; Pedro Mariño de Lobera, Crónica del Reino de Chile; Alonso González de Nájera, Desengaño y reparo de la guerra del Reino de Chile (1614); Alonso de Ovalle, Histórica relación del Reino de Chile y de las misiones y ministerios que ejercita en él la Compañía de Jesús (1646); Santiago de Tesillo, Epitome chileno (1648) y Restauración del Estado de Arauco (1665); Francisco Núñez de Pineda y Bascuñán, Cautiverio feliz (1673) y Suma y epílogo de lo más esencial que contiene el libro intitulado "Cautiverio feliz, y guerras dilatadas del Reino de Chile" (1675); Diego de Rosales, Historia general del Reino de Chile, Flandes indiano (1674). Además de este corpus, he tenido en cuenta también dos crónicas religiosas del Perú: Antonio de la Calancha, Corónica moralizada del orden de San Agustín en el Perú (1639); y Diego de Córdoba Salinas, Crónica franciscana de las provincias del Perú (1651). 
La primera de las menciones que he encontrado a Flandes en el corpus citado nos remonta a mediados del siglo XVI. En la Crónica del Reino de Chile de Mariño de Lobera, el cap. 34 del libro primero está dedicado al descubrimiento de los Estados de Arauco y Tucapel y el cronista nos informa sobre el porqué del nombre de esta región:

Diré aquí la causa de haberse llamado esta tierra los Estados; y fue que al pasar por ella los españoles dijo Jerónimo de Alderete: "Señores míos, bien podemos llamar a esta tierra los Estados de Flandes y Alemania", y refiriéndose este dicho al gobernador, dijo él así: "Llámense los Estados de Arauco y Tucapel”, y con este nombre se han quedado hasta hoy ${ }^{12}$.

El episodio narrado tuvo lugar hacia 1551, poco antes de la fundación de La Imperial por Valdivia en ese mismo año ${ }^{13}$. Faltaban todavía casi dos décadas para la rebelión de los Países Bajos contra el monarca español. El entonces teniente Alderete al comparar estas tierras con Flandes se refería a las bondades de aquellas regiones, la fertilidad de las llanuras que allí se encontraron, evocando de esta manera las similitudes del paisaje y también las riquezas de aquellas provincias. En la crónica, unas líneas antes, Mariño de Lobera había afirmado que Alderete, al descubrir la región "quedó tan satisfecho y alegre que les pareció a él y a los suyos que no había más que buscar en el mundo, mayormente por ser todos los ríos que por allí pasan muy ricos de oro" ${ }^{14}$. Se trata del tópico literario de la riqueza natural de la región descrita que tan presente estuvo en las crónicas de Indias, pero que en este caso nos interesa porque fija, además, la imagen que tenían de Flandes los conquistadores españoles. Resuena, en cierta medida, en estas palabras y en la comparación del refrán recogido por Correas al que me refería previamente.

Las crónicas analizadas guardan silencio sobre Flandes hasta fechas posteriores, avanzado ya el siglo XVII. Sin embargo, antes, en 1590, el

\footnotetext{
12 Mariño de Lobera, Crónica del Reino de Chile 311. El capítulo ocupa las páginas 309 y ss.

13 Como es sabido, fueron precisamente los informes de las riquezas de esta región que Alderete envió al gobernador los que motivaron el viaje de Valdivia.

14 Mariño de Lobera, Crónica del Reino de Chile 311. El cronista nos explica, además, cómo los indígenas salían al encuentro de los españoles a negociar y se refiere al hecho de que no hubiera enfrentamiento alguno, aunque los españoles decidieron salir de aquellas tierras porque comenzaron a ver que los indígenas tal vez cambiaran de actitud.
} 
virrey de Perú, García Hurtado de Mendoza -que a mediados de siglo había sido gobernador de Chile-, en cartas remitidas a Felipe II, le explica cómo era lastimoso ver "la perdición de Chile" porque estaban en guerra no solo los indios de Arauco y su comarca, sino también los de otros muchos valles. Así, continúa el virrey,

lo de Chile se ha convertido en guerra de Flandes, con que ha consumido los indios que había de paz y los vecinos que vivían en los pueblos con sus haciendas y está tan malquisto entre españoles $\mathrm{y}$ indios que el que en esta tierra comete delito quiere más que le envíen a las galeras que no a servir a Chile ${ }^{15}$.

Si seguimos avanzando en el tiempo, encontramos a Alonso González de Nájera, un soldado español que tras haber participado en la guerra de Italia, Francia y Flandes, viajó a Chile en 1600 al mando de una compañía. A mediados de 1607 fue enviado por el gobernador de Chile a la península para informar al rey en su calidad de soldado "del peligroso estado de aquella conquista, cansado [el gobernador] de haber enviado religiosos y personas de papeles" (González de Nájera, Desengaño y reparo 2). Con el objetivo de conseguir que la Corona impulsara un cambio en el modo de desarrollar la guerra contra los mapuches, González de Nájera redactó su Desengaño y reparo de la guerra del Reino de Chile. En 1614 envió la obra al conde de Lemos, Pedro Fernández de Castro, presidente del Consejo de Indias en el momento en que el autor había regresado a la península y visitado la corte ${ }^{16}$.

En esta obra hallamos varias referencias en las que el cronista compara las guerras de Chile y Flandes. Sin embargo, en el caso de González de Nájera se trata de comparaciones que surgen al hilo de su relato, al tratar de explicar aspectos militares de la guerra vivida en Chile, ilustrándolos con sucesos similares que recuerda de su paso por Flandes. Así, la guerra en la frontera de Chile es tanto o más dura que cualquier otra porque, "consideradas las dificultades y casi intolerables trabajos" con que se hacen los servicios, "hecha comparación a los de Flandes, doy como quien ha experimentado

15 "Fragmento de carta del virrey García Hurtado de Mendoza a su majestad...", 1 de mayo de 1590 (cit. en Medina, vol. IV: 121-123, la cita es de la página 122). En otra carta del virrey a Felipe II (cit. en Pease García-Yrigoyen y Moya Pons vol. 2: 297), Hurtado de Mendoza afirma que la guerra de Chile era "con respecto al Perú lo que Flandes para España".

16 A la altura de 1614, Pedro Fernández de Castro era virrey de Nápoles, tal y como consta en la dedicatoria del libro. 
unos y otros, la ventaja a los de Chile, aunque guerra de menor máquina” (133). En este sentido, en cuanto a las bajas producidas en el país trasandino,

viendo lo caro que cuesta a su majestad el poner en ella cada soldado por ser en tierra tan remota, y las inferiores armas de los enemigos respeto de las de otros de Europa, se pueden tener estas por tan grandes pérdidas como las que lo han sido en Flandes o en otras guerras de diferente máquina (80).

Por ello, González de Nájera animaba a "honrar y favorecer la milicia” chilena para que quienes participaran pudieran

tener por blasón el haber servido algún tiempo en la frontera de Chile, de suerte que no tenga menos nombre y reputación aquella guerra en todas las Indias y ante los ojos de su majestad y sus consejos del que ha tenido en ellos y en toda Europa la de Flandes, pues aunque de indios, son tan hombres cuanto lo han mostrado en los muchos años que se han sabido defender no de otros indios, sino de españoles $(239)^{17}$.

Un cuarto de siglo después de que González de Nájera concluyera su crónica sobre el Reino de Chile, en 1639, el agustino fray Antonio de la Calancha publicaba su Corónica moralizada del orden de San Agustín en el Perú. En el texto, Calancha hace una alusión a Flandes cualitativamente distinta de las que hiciera González de Nájera y que recuerda más las palabras de García Hurtado de Mendoza a finales del siglo XVI. En el capítulo 15, dedicado a "los gobiernos y reyes ingas", cuando habla sobre el inca Tupac Yupangui, hace un breve comentario desviándose completamente del hilo narrativo y se refiere a Chile como "segundo Flandes del mundo y primero del Perú":

Este inga conquistó hacia el norte hasta adelante de Quito, pasada la línea, y hacia el sur llegó hasta Chile, segundo Flandes del mundo y primero del Perú, y es que no corrió el situado y las pagas por mano de ministros codiciosos ni se disponía la guerra por consejo de interesados (99).

$17 \quad$ Hay otros casos en que el cronista recurre a Flandes a la hora de establecer otro tipo de símiles, todos ellos en la misma línea de los ya mencionados. Ver, por ejemplo, páginas 90, 147, 235. 
De las palabras del agustino se desprende una lectura de una gran carga crítica al dar a entender que había sido la corrupción de la administración la que había hecho que la guerra de Chile se convirtiera para los españoles en un segundo Flandes, en contraste con lo que el inca Tupac Yupangui consiguiera tiempo atrás.

Las referencias a la guerra de Flandes continuaron apareciendo en las crónicas chilenas -y en fuentes peninsulares, tal y como antes he mencionado- también después de la paz de Münster de 1648. De hecho, en otra crónica religiosa de mediados del siglo XVII, la Crónica franciscana de las provincias del Perú que escribiera Diego de Córdoba Salinas en 1651, el autor relacionaba el carácter indómito, belicoso y cruel de los indígenas de Chile con el "clima, temperamento y constelación de aquellos países". Así, aquella gente pone

toda su felicidad y reputación en defender su libertad, sin yugo de otro dominio. El sumo trabajo con que el general Pedro Valdivia fatigó a los indios, para la saca y beneficio del oro de las minas, les ocasionó el alzamiento general, que hicieron el año de 1553 y en sangrienta batalla vencieron y mataron con bárbara crueldad a Valdivia. Este alzamiento general dura hasta hoy, con otros que se han continuado, $\mathrm{y}$ se ha hecho tan valiente e inexpugnable aquella nación que viene hoy a ser Chile, para el América, lo que fue Numancia contra el poder de Roma, Cantabria contra la felicidad de Augusto César y Flandes para la augusta casa de Austria (1100).

Diego de Córdoba, en este pasaje, desarrolla la idea y rescata de la historia y del debate historiográfico del momento no solo la más reciente situación de Flandes, sino que se retrotrae a la época romana y recuerda la mítica resistencia numantina y cántabra contra el imperio romano. La comparación no discrimina en clave nacional lo que unos y otros simbolizaban. Diego de Córdoba mantiene en un mismo plano tanto la lucha de los indígenas chilenos y los flamencos contra los intereses de la Monarquía Hispánica como las míticas resistencias de cántabros y numantinos frente a la invasión romana de la península. Estos últimos casos tenían ya a la altura de mediados del siglo XVII evidentes sentidos y connotaciones de reivindicación de una identidad española y podrían haber sido contemplados por el franciscano como ejemplos bien distintos, contrarios en realidad, del chileno y el flamenco ${ }^{18}$. Diego de

18 Por otro lado, Diego de Córdoba conocería sin duda la Historia general de España de Juan de Mariana, de 1601, así como el debate suscitado en torno al cantabrismo en los 
Córdoba se limita por tanto a incorporar dos nuevos ejemplos del tópico heroico y no desarrolla en su relato, asociado a ellos, elemento identitario alguno, como sí hiciera Mariana, por ejemplo, para el caso numantino ${ }^{19}$.

Un año antes de la firma de la paz de Münster, en 1647 se publicó en Madrid, en la Imprenta Real, la Guerra de Chile, causas de su duración, medios para su fin, obra de Santiago de Tesillo, maestre de campo en Chile y corregidor de la ciudad de Concepción. La obra iba dirigida a Juan de Santelices Guevara, miembro del Consejo de Castilla. En la aprobación que acompaña al texto de Tesillo, firmada por Gaspar de Escalona Agüero, oidor de la Real Audiencia de Chile, el licenciado comienza advirtiendo cómo "De la montaña es la pluma que escribe esta historia de Chile, rebelde Flandes de nuestro occidente" (Tesillo, Guerra de Chile). Tesillo no se refiere en este texto a Chile como un segundo Flandes, pero encontramos en sus folios una referencia clara a lo que representaban las provincias unidas para él: Flandes era la "plaza de armas del mundo" y el "centro de la guerra" (Tesillo, Guerra de Chile, fol. 42v).

Al año siguiente, 1648, Tesillo publicó otra obra, esta vez en Lima: el Epitome chileno, ideas contra la paz, dedicada a García Sarmiento de Sotomayor, que aquel mismo año había pasado de ser virrey de Nueva España a ocupar el cargo de virrey del Perú. El título ya nos da alguna pista sobre la línea discursiva del autor: "El hacer la guerra -nos dice- es el fin de la guerra, es el medio único de la paz, y si se atiende a la paz, será perpetuar la guerra" (Tesillo, Guerra de Chile, fol. 27v). Unos folios antes, tras explicar cómo la guerra defensiva había hecho que el conflicto se perpetuara al dar opción al enemigo de descansar, crecer y hacerse más poderoso, nos informa de cómo finalmente se habían buscado nuevos medios de acabar con el problema:

Atrevíanse a pensar los que cursaban aquella militar política, aquel nuevo Flandes, que era incurable la llaga desta guerra, y aun imposible

siglos XVI y XVII y las elaboraciones vascongada y navarra, que se presentaban como los verdaderos herederos de aquellos cántabros que tan heroicamente resistieron al imperio romano. Ver al respecto la obra de Wulff; también Leoné Puncel 92 y ss., entre otros. Tampoco sería desconocida para el cronista franciscano la tragedia cervantina La Numancia, que camina también en esa construcción de "nuevas imágenes del pasado que explicaran y ensalzaran la posición alcanzada" por España en la política europea (Wulff 18).

19 Numancia era para el jesuita talabricense temblor "y espanto del pueblo romano, gloria y honra de España” (Mariana, vol. I: 59, cit.en Wulff 52). 
en muchos siglos conseguir la paz; ocasionábaseles la desconfianza de infinitos presagios, como si por ventura no se pudiesen evitar los hados o como si hubiera algún mal sin remedio (Tesillo, Guerra de Chile fol. $17 \mathrm{v})$.

El problema de Flandes se repetía, por tanto, en Chile. Varios años más tarde, en 1665, Tesillo publicaba, también en Lima, una breve relación titulada Restauración del Estado de Arauco y otros progresos militares... Se trataba de un breve texto de apenas 18 folios. En este caso, como en la Guerra de Chile, en la obra no se hace ninguna referencia a Flandes, pero sí la encontramos en la aprobación que firmara Pedro González de Güemes, oidor de la Real Audiencia de Lima. Elogiando la labor llevada a cabo por Francisco de Meneses, gobernador de Chile a quien va dedicada la obra, González de Güemes explica los avances en la guerra contra los indígenas y dice:

habían de tener mucho antes en teórica y práctica los grandes capitanes que han gobernado a Chile para que, poblando como se hace al presente, se diese fin a tan enconada y tenaz guerra, y más con el fomento continuado y con el ardiente fervor con que vuestra excelencia mejora felizmente los buenos efectos de aquellas armas y de aquel nuevo Flandes, emporio de maravillosos sucesos de nuestros invictos españoles ${ }^{20}$.

Nuevamente, podemos ver cómo la referencia a la guerra en el Arauco, el recuerdo de "tan enconada y tenaz guerra" lleva a pensar en Chile como un "nuevo Flandes", en palabras del maese de campo. En este caso, como en los anteriores, no hay una mayor elaboración de la imagen, pero no deja de ser significativo el hecho de que tanto Tesillo, como los oidores Gaspar de Escalona Agüero y Pedro González de Güemes, tuvieran presente esta idea.

Un ejemplo que me parece especialmente interesante es el Cautiverio feliz de Francisco Núñez de Pineda y Bascuñán, ultimado en 1663 y completado con algunos añadidos y correcciones en 1673 (Ferreccio Podestá y Kordic Riquelme, vol. 1: 7) ${ }^{21}$, cuando España y Holanda eran ya firmes aliados en el contexto de la guerra franco-holandesa. Dos años después, en 1675, está

20 "Aprobación del señor doctor don Pedro Gonzales de Güemes" (Tesillo, Restauración del Estado de Arauco, fol. 1v).

$21 \quad$ Correa Bello fecha la redacción del Cautiverio entre 1656 y 1664 y cita una carta de Bascuñán en que afirma tener ya terminada la obra a la altura de 1664 (67-69). 
fechada la Suma y epílogo de lo más esencial que contiene el libro intitulado "Cautiverio feliz, y guerras dilatadas del Reino de Chile", una suerte de revisión que hiciera su propio autor al ver que su extensa obra no era publicada ${ }^{22}$. En el capítulo que Bascuñán trasladara del Cautiverio feliz a la Suma, el militar y escritor nacido en Chillán nos dice cuál era la intención con la que había abordado la labor de escritura y, al hacerlo, reelabora un pasaje del Cautiverio que resulta de lo más significativo "solo sí podré decir y dar a entender lo que me ha movido a poner la pluma en la mano y escrebir algunos sucesos deste chileno y nuevo Flandes con verdaderas experiencias, aunque con humilde y común estilo" (Suma y epílogo de lo más esencial 98).

Es interesante comprobar que en el Cautiverio feliz, terminado, como decía, tan solo unos años antes que la Suma, no existía la referencia a este "chileno y nuevo Flandes", sino que el pasaje había quedado de la siguiente manera: "solo sí podré decir y dar a entender lo que me ha movido a coger la pluma en la mano y escrebir algunos susesos de este reino con verdaderas experiencias -aunque con humilde y llano estilo" (Cautiverio feliz, vol. 1:236).

Al tratar de explicar la razón de esta variante, cabe preguntarse si Núñez de Pineda y Bascuñán pudo haber leído una copia del manuscrito de Diego de Rosales o, al menos, haber tenido noticia de su redacción -y del título que había dado a la crónica-, sobre todo teniendo en cuenta que a lo largo de las páginas del Cautiverio feliz no hay ninguna mención a Chile como un nuevo Flandes. Y esto resulta especialmente llamativo si tenemos en cuenta que el objetivo de la obra de Bascuñán era el de "dar a entender las causas que se me ofresen para la dilación y perpetuidad de esta guerra de Chile" (Cautiverio feliz, vol. 1: 404) 23. $^{23}$

Sabemos, porque el propio autor así nos lo indica, que Diego de Rosales sí conoció la obra de Núñez de Pineda y Bascuñán ${ }^{24}$. Cuando el jesuita se refiere al episodio del cautiverio del militar chileno nos dice que "de su captiverio hizo un curioso libro, porque fueron muchas cosas las que en él le sucedieron de gusto; si sale a luz se podrá ver en él" (Rosales, Historia

22 Ver al respecto el estudio preliminar de José Anadón en la edición de la Suma y epílogo de Núñez de Pineda y Bascuñán. El autor ya había tratado el tema en otros trabajos anteriores (Anadón 1977 y 1978).

23 Se trata de una idea que aparece de modo insistente en diferentes lugares de la crónica.

24 Además, tal y como indica Correa Bello (17), de la obra de Bascuñán circularon varias copias. 
general de el Reino de Chile, vol. 3: 67) ${ }^{25}$. No tenemos en cambio la seguridad, o al menos yo no la he encontrado, de que Bascuñán, cuando compuso la Suma, hubiera tenido conocimiento de la obra de Rosales. Es cierto que, como hemos visto, otros autores ya se habían referido con anterioridad a Chile como otro Flandes y, por tanto, las fuentes de Bascuñán a la hora de hablar del "chileno y nuevo Flandes" podrían haber sido otras. Cabe también la posibilidad de que él mismo llegara a formular la expresión. Sin embargo, el hecho de que no hubiera aparecido en el Cautiverio y sí se incluyera en el capítulo que Bascuñán trasladó a la Suma nos hace pensar que, al menos, pudo haber tenido noticia del título de la obra del jesuita.

Hay también otros datos que pueden sustentar esta hipótesis. Rosales concluyó su Historia general del Reino de Chile hacia 1674, pero el manuscrito estaba terminado y preparado para su publicación ya para la altura de 1666, año en que están fechadas las aprobaciones y en que la crónica fue llevada a Europa para su publicación por el padre Lorenzo de Arizábalo ${ }^{26}$. Una de las censuras, la firmada por Juan de San Buenaventura, recoge el título Historia general y Conquista temporal y Espiritual deste Reino de Chile y Flandes Indiano, de forma que la expresión queda confirmada al menos a la altura de 1666. Por otro lado, Rosales y Bascuñán se conocían, ya que ambos habían coincidido en 1656 en las difíciles circunstancias del cerco y liberación de Boroa $^{27}$. Queda esta línea de trabajo, entre otras, como una de las posibles vías de exploración ${ }^{28}$.

25 Benjamín Vicuña Mackenna, en su edición del Cautiverio, afirma en nota al pie que Rosales incluso conoció el libro manuscrito de Bascuñán por las similitudes en que se refieren a los incidentes del cautiverio y rescate (vol. 3: 67, n. 1). En este mismo sentido se ha manifestado también Correa Bello (17-18).

26 El periplo sufrido por el manuscrito de la obra de Rosales ha sido reconstruido por Hanisch Espíndola (1985).

$27 \quad$ En el momento en que los indígenas cercaron Boroa en el lugar residía un hijo de Bascuñán y se encontraba también el propio Rosales. El autor del Cautiverio, gobernador de la frontera, había salido en ayuda de Juan de Salazar, pero él mismo dirigió la liberación de Boroa y condujo posteriormente a los rescatados a Concepción. Ver al respecto, Núñez de Pineda y Bascuñán, Cautiverio feliz, vol. 2: 576-580); Anadón (Pineda y Bascuñán 119 y ss.).

28 José Anadón (Pineda y Bascuñán 210) ya apuntó el interés de analizar las posibles relaciones entre Bascuñán y Diego de Rosales, Santiago de Tesillo, Alonso de Ovalle y Gaspar de Villarroel, autores contemporáneos que compartían la defensa de los indios araucanos. 


\section{DIEGO DE ROSALES: EL FLANDES INDIANO}

Tal y como hemos podido comprobar, Antonio de la Calancha y Diego de Córdoba Salinas habían utilizado la imagen de Chile como un segundo o nuevo Flandes antes que de que Rosales acuñara la expresión "Flandes indiano". También lo habían hecho Santiago de Tesillo en su Epitome chileno (1648) y Pedro González de Güemes en la aprobación de otra obra de 1665 de este mismo autor. Está, además, la referencia de Núñez de Pineda y Bascuñán en la que me he detenido líneas atrás y que supone un testimonio más, fuera o no consecuencia de haber tenido noticia de la obra del jesuita. Me interesa, en este momento, dedicar un breve espacio a analizar la forma y el alcance de la asociación que Rosales hizo entre Flandes y Chile a la altura de 1674.

Rosales fija en su dedicatoria a Carlos II y en el breve texto dirigido "Al lector", el sentido general de su obra. Con las siguientes palabras ofrece su libro al rey:

en que los indios de Chile, después de sus porfiadas y sangrientas guerras, comenzaron a dar la paz y obediencia debida a vuestra majestad, y aunque la alternaron con guerras y alzamientos, al fin se sujetaron todos; y al gobernador don Juan Enríquez, que hoy gobierna, le dieron la paz ciento y cuatro provincias y tiene muchos millares de indios reducidos a la obediencia de vuestra majestad y deseosos de sujetarse a la divina y de recebir su Santa Fe Católica ${ }^{29}$.

La idea del sometimiento de los indígenas chilenos vuelve a aparecer en el texto dirigido "Al lector" resaltando que la "valentía española" había conseguido con 160 combatientes lo que el Inca no obtuvo con cien mil, "enfrenando al indómito araucano, al imperial altivo y al valdiviano soberbio". Aunque los indígenas habían peleado por liberarse de la presencia española como lo habían hecho con los incas, no pudieron lograrlo:

Y en esta vana pretensión se han consumido y han consumido más de cuarenta y cuatro mil españoles (gran numero para las Indias, donde hay tan pocos) y han obligado a gastar a la Real Hacienda treinta y nueve millones, eternizando su porfía la guerra en Chile y dilatándola por siglos, pues ya ha pasado uno y se va continuando otro desde 
que comenzó esta guerra con el primer descubridor Almagro, año de 1535, hasta el de 1673, en que la va dando fin el gobernador don Juan Enríquez (vol. 1: LIV).

Rosales comienza por tanto refiriéndose a la constante de la guerra de Chile, que tanto tiempo había perdurado y que tantas vidas y medios se había llevado. En la obra del jesuita, la idea de Flandes aparece en varios lugares, más allá del propio título. Sin embargo, la crónica no representa un desarrollo de la idea más allá de los ejemplos que hemos podido ver hasta ahora. De hecho, en su mayor parte las menciones del jesuita a los holandeses o a Flandes se limitan a informarnos del ataque a Valdivia y sí añade algún comentario sobre las prácticas comerciales en tierras americanas como manera también de extender sus creencias ${ }^{30}$. Únicamente en cuatro breves pasajes Rosales se refiere a Chile como un nuevo Flandes. Dos de estas menciones se encuentran en las primeras páginas de la crónica, concretamente en el capítulo 4 del primer libro. En ellas el autor hace referencia a la prolongación ya por 130 años de la guerra de Chile, motivo por el que el país se había convertido en un auténtico "Flandes indiano":

Los españoles que por tierra han descubierto y poblado este Reino de Chile han tenido bien en qué ejercitar su valor, hallando en él un Flandes indiano, una sangrienta guerra, una valiente oposición y osada resistencia en los naturales desta tierra, que desde el año de 1545 hasta este de 1674 han sustentado la guerra contra el poder español, contra tantos gobernadores valerosos y ejercitados capitanes de Flandes, por espacio de ciento y veinte y nueve años (vol. 1: 18-19) ${ }^{31}$.

30 Rosales afirma que tras la firma de la paz con los Países Bajos, los holandeses habían incumplido el acuerdo de no comerciar en las posesiones españolas de América y "en perjuicio de los reales haberes y contratación del Perú y Sevilla, han comerciado en Buenos Aires y otros puertos del mar del Norte e islas de Barlovento, con manifiesta contingencia de que la herejía inficione la pureza de la ley católica que tan limpia profesan los españoles en estas Indias" (vol. 1: 58).

31 La idea ya había aparecido poco antes: los araucanos chilenos "se han mostrado tan feroces y valerosos que por muchos años, y por mas de un siglo entero, han hecho oposición gallarda al poder español", haciendo de "Chile un Flandes indiano" (15-16). Hanisch Espíndola publicó una segunda dedicatoria de la obra a Carlos II en la que también encontramos una referencia a "este Flandes Indiano" (95-96). Esta segunda dedicatoria no fue incorporada, sin embargo, a la edición revisada que preparó Mario Góngora en 1989. 
Una referencia similar se da en el capítulo 12 del séptimo libro. Rosales relata la llegada en 1630 del nuevo gobernador, Francisco Laso de la Vega, y explica cómo la fama de su valor y de sus grandes servicios en la guerra de Flandes habían precedido al militar español. Tanto era así que "a todos se les avivaron las esperanzas de lo mucho que había de obrar en este Flandes segundo de Chile y sin segundo en las Indias" (vol. 3: 70).

Todas las menciones referidas caminan, por tanto, por una línea similar a las ya citadas de Antonio de la Calancha, Diego de Córdoba Salinas, Santiago de Tesillo y Núñez de Pineda y Bascuñán. Además de ellas, Rosales comparó el río Biobío con el Rin y el Escalda. "Ha granjeado en Chile Biobío igual fama que el río Rin y Esquelda, en Flandes" escribió el jesuita (vol. 3: 265). Sin embargo, tal y como he dicho, el desarrollo de la imagen que compara Chile y Flandes no fue más allá de estas breves referencias y, sobre todo, del recuerdo de la guerra.

\section{CONCLUSIÓN}

Desde mediados del siglo XVI hasta el último tercio del siglo XVII, las referencias que podemos encontrar en las crónicas chilenas a lo que Flandes representaba o simbolizaba para los súbditos de la Monarquía Hispánica van cambiando. La evolución que se produce desde la imagen positiva que encontramos en la frase "No hay más Flandes", hasta la consolidación de la fórmula del "Flandes indiano" de Rosales nos habla de la influencia de la guerra en la construcción de una imagen de Flandes -y de Chile- por parte de los españoles. En el caso chileno, no parece que se trate de una idea generalizada y extendida que vaya evolucionando poco a poco, llenándose de contenido hasta tomar cuerpo en la feliz expresión del cronista jesuita. Sin embargo, y a pesar de ello, tampoco nos hallamos ante una formulación que surja como una idea original y nunca antes expresada.

Antes de que el jesuita Diego de Rosales hablara de Chile como un "Flandes indiano", la mención al país andino como un nuevo Flandes había aparecido en dos crónicas religiosas - la del agustino Antonio de la Calancha y la del franciscano Diego de Córdoba Salinas- y en tres obras de Santiago de Tesillo que podríamos calificar como de contenido más político y militar. Al margen de las crónicas chilenas más tempranas, anteriores a la imagen misma de Flandes como el gran problema de la corona española, es importante tener en cuenta que la referencia, ya apuntada por el virrey del Perú, García 
Hurtado de Mendoza, en 1590, no hubiera encontrado eco en varias de las obras de finales del XVI y principios del XVII. No se trataba por tanto de una constante o una idea común, compartida por todos los historiadores de Chile.

Sin embargo, los ejemplos de esa identificación entre Chile y Flandes son lo suficientemente importantes como para pensar que se trata de una imagen recurrente, como lo era también en la península al hablar de Cataluña o las posesiones españolas en Italia. El rastreo que hemos podido llevar a cabo en la correspondencia de los virreyes del Perú y de los gobernadores de Chile ha sido insuficiente de cara a poder analizar con seguridad el grado de implantación de esta imagen en los gobernantes de aquella tierra de frontera. Sería interesante ver hasta qué punto esa imagen de un "Flandes indiano" pudo haber estado presente, más allá de una aparición puntual en una carta de García Hurtado de Mendoza al rey, en el día a día de la administración virreinal con anterioridad a que fuera llevada al papel por la pluma de los cronistas. Y sería interesante también ver si en esta documentación la presencia de la comparación con Flandes responde también a problemas o sucesos concretos. Así como en el viejo continente hemos podido ver con claridad cómo la imagen de un nuevo o segundo Flandes aparece asociada a un hecho concreto (Aragón en 1591, Cataluña en 1642 y Messina en 1673), en el caso de Chile, por la propia naturaleza de las fuentes empleadas, no queda clara la causa que pudo dar lugar a la asociación de ideas, más allá de la presencia constante de la guerra. Evidentemente, las crónicas chilenas carecen de la inmediatez de la documentación y no podemos establecer esa relación de causa/efecto. No era ese, en cualquier caso, el objetivo del presente trabajo $\mathrm{y}$ esta idea queda pendiente para una futura ocasión.

La dureza de la guerra en la Araucanía, la prolongación de dicha guerra en el tiempo y su presencia constante en la vida chilena, la imposibilidad de encontrar un final al conflicto, el enorme coste económico que suponía para las arcas reales junto a otros aspectos más concretos como la presencia en el país andino de veteranos de la guerra en los Países Bajos, la constitución de un cuerpo de soldados que se estableció en la región de manera permanente y los intentos holandeses de aliarse con los araucanos y asentarse en la región, fueron sin duda aspectos que propiciaron la asociación de ideas entre Chile y Flandes. He tratado de mostrar de qué formas se fue explicitando esa asociación y en qué contextos y con qué significaciones se plasmó. Se trata, sin duda, de un tópico, pero que cobra formas nuevas y que se llena de nuevos significados en contextos históricos y literarios diferentes. 
Por otra parte, no parece que el recuerdo de la guerra de Flandes haya tenido una lectura en clave identitaria en las obras consultadas. No se trata, evidentemente, de acontecimientos que permitan una interpretación elogiosa de la Monarquía Hispánica, pero sí podrían haber servido para elaborar un discurso del enemigo de España que, sin embargo, no hemos encontrado. El ejemplo que en este sentido resulta más ilustrador tal vez sea el de Diego de Córdoba. Una excepción serían las obras de Santiago de Tesillo, que bien merecen un estudio aparte.

Quedan, como se puede comprobar, muchas preguntas por resolver, pero espero haber mostrado al menos el proceso y los contextos en que Flandes se hizo presente en el discurso que se elaboró sobre el Reino de Chile en las crónicas de los siglos XVI y XVII.

\section{BIBLIOGRAFÍA}

Anadón, José. Pineda y Bascuñán, defensor del araucano. Vida y escritos de un criollo chileno del siglo XVII. Santiago de Chile: Editorial Universitaria, 1977.

Prosistas coloniales del siglo XVII: Rosales y Pineda Bascuñán. Santiago de Chile: Seminario de Filología Hispánica, 1978.

“Estudio preliminar”. Núñez de Pineda y Bascuñán, Francisco. Suma y epílogo de lo más esencial que contiene el libro intitulado "Cautiverio feliz, y guerras dilatadas del Reino de Chile". Ed. J. Anadon y R. A. McNeil. Santiago de Chile: Sociedad Chilena de Historia y Geografía/Ediciones Universidad Católica de Chile, 1984. 13-31.

Barbier, Jacques A. Reform and Politics in Bourbon Chile, 1755-1796. Ottawa: University of Ottawa Press, 1980.

Calancha, fray Antonio de la. Corónica moralizada del Orden de San Agustín en el Perú... Barcelona: Por Pedro Lacaballería, 1639.

Córdoba Salinas, Diego de, Crónica franciscana de las provincias del Perú. Ed. L. G. Canedo. Washington: Academy of American Franciscan History, 1957.

Correa Bello, Sergio. El Cautiverio feliz en la vida política chilena del siglo XVII. Santiago de Chile: Editorial Andrés Bello, 1965.

Correas, Gonzalo. Vocabulario de refranes y frases proverbiales. Ed. R. Zafra. Pamplona/ Kassel: Universidad de Navarra/Edition Reichenberger, 2000 (edición en CD-ROM).

Covarrubias Horozco, Sebastián de. Tesoro de la lengua castellana o española. Ed. I. Arellano y R. Zafra. Madrid/Frankfurt am Main: Iberoamericana/Vervuert, 2006.

Cruz de Amenábar, Isabel. Arte y sociedad en Chile, 1550-1650. Santiago de Chile: Universidad Católica de Chile, 1986.

"Diario del ejército español en las comarcas de Tarragona". Real Academia de la Historia. Memorial histórico español. Colección de documentos, opúsculos y antigüedades. Madrid: Imprenta y Fundición de Manuel Tello, 1891, vol. 23, 380-547. 
Ferreccio Podestá, Mario y Raïsa Kordic Riquelme. "Prólogo" a su ed. de Núñez de Pineda y Bascuñán, F. Cautiverio feliz. Santiago de Chile: Gobierno de Chile, Consejo Nacional de Fomento del Libro y la Lectura/Universidad de Chile, Seminario de Filología Hispánica/ Ril Editores, 2001. 7-10.

Góngora Marmolejo, Alonso de. Historia de todas las cosas que han acaecido en el reino de Chile y de los que lo han gobernado. Ed. M. Donoso Rodríguez. Madrid: Iberoamericana, 2010.

González de Nájera, Alonso. Desengaño y reparo de la guerra del Reino de Chile. Ed. J. T. Medina. Santiago de Chile: Imprenta Ercilla, 1889.

Guarda, Gabriel, o.s.b. Los laicos en la cristianización de América. Santiago de Chile: Ediciones Nueva Universidad, 1973.

Flandes indiano. Las fortificaciones del Reino de Chile, 1541-1826. Santiago de Chile: Ediciones Universidad Católica de Chile, 1990.

Hanisch Espíndola, Walter (s. j.)."El manuscrito de la Historia general de Chile del P. Diego de Rosales y su larga peregrinación". Jahrbuch für Geschichte Lateinamerikas/Anuario de Historia de América Latina 22 (1985): 69-97.

Lázaro Ávila, Carlos. Las fronteras de América y los "Flandes indianos". Madrid: CSIC, 1997.

Leoné Puncel, Santiago. Los Fueros de Navarra como lugar de la memoria. Donostia-San Sebastián: Fundación para el Estudio del Derecho Histórico y Autonómico de Vasconia, 2005.

Marañón, Gregorio. Antonio Pérez (el hombre, el drama, la época). Madrid: Espasa-Calpe, 1958 [ $1^{\text {a }}$ ed. 1947], 2 vols.

Mariño de Lobera, Pedro. Crónica del Reino de Chile, escrita por el capitán D. Pedro Mariño de Lobera, dirigida al excelentísimo Sr. D. García Hurtado de Mendoza, marqués de Cañete, vicerrey y capitán general de los Reinos del Perú y Chile, reducida a nuevo método y estilo por el padre Bartolomé de Escobar, de la compañia de Jesús, en Crónicas del Reino de Chile. Ed. F. Esteve Barba. Madrid: Atlas, 1960. 225-562 (BAE, 131).

Medina, José Toribio. Colección de documentos inéditos para la Historia de Chile. Segunda serie, t. IV, 1590-1594. Alonso de Sotomayor-Martín Oñez de Loyola. Santiago de Chile: Fondo Histórico y Bibliográfico J. T. Medina, 1960.

M.T.A."Noticiario del siglo XVII". Archivo de Filología Aragonesa 1 Serie B (1945): 347-375.

Nunes Adão, Clicie Rosana. "Chile holandés o Flandes indiano en la visión de Gaspar Barléu". El desafio holandés al dominio ibérico en Brasil en el siglo XVII. Ed. J. M. Santos Pérez y G. F. Cabral de Souza. Salamanca: Ediciones Universidad de Salamanca, 2006. 237-254.

Núñez de Pineda y Bascuñán, Francisco. Cautiverio feliz. Ed. M. Ferreccio Podestá y R. Kordic Riquelme. Santiago de Chile: Gobierno de Chile, Consejo Nacional de Fomento del Libro y la Lectura/Universidad de Chile, Seminario de Filología Hispánica/Ril Editores, 2001, 2 vols.

Suma y epílogo de lo más esencial que contiene el libro intitulado "Cautiverio feliz, y guerras dilatadas del Reino de Chile". Ed. J. Anadon y R. A. McNeil. Santiago de Chile: Sociedad Chilena de Historia y Geografía/Ediciones Universidad Católica de Chile, 1984.

Ovalle, Alonso de. Histórica relación del Reino de Chile y de las misiones y ministerios que ejercita en él la Compañia de Jesús. Roma: Francisco Cauallo, 1646. 
Pease García-Yrigoyen, Franklin y Frank Moya Pons. Dirs. Historia general de América Latina. II, El primer contacto y la formación de nuevas sociedades. Valladolid: Trotta, 2000.

Quevedo, Francisco de. Pregmática de aranceles generales, por Francisco de Quevedo y Villegas, poeta de cuatro ojos, en Prosa festiva completa. Ed. C. C. García Valdés. Madrid: Cátedra, 1993.164-183.

Rivero Rodríguez, Manuel. La edad de oro de los virreyes. El virreinato en la Monarquía Hispánica durante los siglos XVI y XVII. Madrid:Akal, 2011.

Rosales, Diego de. Historia general de el Reino de Chile, Flandes indiano. Ed. B. Vicuña Mackenna. Valparaíso: Imprenta del Mercurio, 1877-1878, 3 vols.

Historia general de el Reino de Chile, Flandes indiano. Ed. revisada por M. Góngora. Santiago de Chile: Editorial Andrés Bello, 1989, 2 vols..

Tesillo, Santiago de. Guerra de Chile, causas de su duración, medios para su fin, ejemplificado en el gobierno de don Francisco Laso de la Vega. Madrid: Imprenta Real, 1647.

Epítome chileno, ideas contra la paz. Lima: Por Jorge López de Herrera, 1648.

Restauración del Estado de Arauco y otros progresos militares conseguidos con las armas de su majestad por mano del señor general de la artillería, don Francisco de Meneses, gobernador y capitán general deste Reino de Chile, y presidente de su Real Audiencia [1665]. Ed. facsímil J. Jijón y Caamaño. Quito: Imprenta de la Universidad Central, 1923.

Usunáriz, Jesús María. “América en la política internacional española de la primera mitad del siglo XVII a través de las crónicas y relaciones de sucesos". Discursos coloniales: texto y poder en la América latina. Ed. P. Latasa. Madrid: Iberoamericana, 2011. 167-186.

"La imagen del enemigo exterior en las crónicas y relaciones de sucesos del siglo XVI", ponencia presentada en el congreso internacional "Imagen y realidad: el universo simbólico del poder en el Siglo de Oro" (Pamplona, 12-14 de diciembre de 2011), en prensa.

Valdivia, Pedro de. Cartas de don Pedro de Valdivia al emperador Carlos V, en Colección de Historiadores de Chile y documentos relativos a la historia nacional. Santiago de Chile: Imprenta del Ferrocarril, 1861, t. I. 1-62.

Vicuña Mackenna, Benjamín. "Vida de Diego de Rosales". Rosales, D. de, Historia general de el Reino de Chile, Flandes indiano. Ed. B. Vicuña Mackenna. Valparaíso, Imprenta del Mercurio, 1877, vol. 1, XI-XXXVII.

Vivar, Jerónimo de. Crónica y relación copiosa y verdadera de los reinos de Chile. Ed. I. A. Leonard y G. Feliú Cruz. Santiago de Chile: Fondo Histórico y Bibliográfico José Toribio Medina, 1966 [1558].

Wulff, Fernando. Las esencias patrias. Historiografía e Historia Antigua en la construcción de la identidad española (siglos XVI-XX). Barcelona: Crítica, 2003. 